This is the final peer-reviewed accepted manuscript of:

Avanzi, L., Fraccaroli, F., Castelli, L., Marcionetti, J., Crescentini, A., Balducci, C., \& van Dick, R. (2018). How to mobilize social support against workload and burnout: The role of organizational identification. Teaching and Teacher Education, 69, 154-167. https://doi.org/10.1016/i.tate.2017.10.001

The final published version is available online at:
$\underline{\text { https://doi.org/10.1016/j.tate.2017.10.001 }}$

Rights / License:

The terms and conditions for the reuse of this version of the manuscript are specified in the publishing policy. For all terms of use and more information see the publisher's website.

This item was downloaded from IRIS Università di Bologna (https://cris.unibo.it/)

When citing, please refer to the published version. 


\section{How to mobilize social support against workload and burnout: The role of organizational identification}

Lorenzo Avanzi a, *, Franco Fraccaroli a, Luciana Castelli b, Jenny Marcionetti b, Alberto Crescentini b, Cristian Balducci c, Rolf van Dick d

a Department of Psychology and Cognitive Science, University of Trento, Italy

Department of Education and Learning (DFA), University of Applied Sciences and Arts of Southern Switzerland, Locarno, Switzerland c Department of Political and Social Sciences, University of Bologna, Italy

$\mathrm{d}$ Institute of Psychology and Center for Leadership and Behavior in Organizations, Goethe University Frankfurt, Germany

Published on:

Teaching and Teacher Education 69 (2018) 154-167 


\begin{abstract}
Recent theoretical and empirical research outlined the role of organizational identification in the stress process. We provide an empirical test of the social identity model of stress by testing a two-step mediation model of the identification-burnout link. We hypothesize that strongly identified teachers will receive more support from colleagues which, in turn, relates to perceptions of reduced workload, which finally leads to both lower work- and studentrelated burnout. We tested our model in a large cross-sectional sample of 2,685 Swiss teachers representing half of the teacher population of Ticino Canton. Hypotheses were supported. Implications for theory and practice are discussed.
\end{abstract}

Keywords: Social identity model of stress, organizational identification, teacher burnout, social support, workload 


\section{Introduction}

Teacher burnout represents not only a problem for the individual teacher but also for schools and for the educational system in general (Aloe, Shisler, Norris, Nickerson, \& Rinker 2014; Guglielmi \& Tatrow, 1998). On the one hand, there are human and economic costs associated with burnout, for example in terms of increased teachers' absenteeism, turnover, health problems and job dissatisfaction (Carson, Baumgartner, Matthews, \& Tsouloupas, 2010; Hakanen, Bakker, \& Schaufeli, 2006; Author \& Author, 2001, 2002), and, on the other hand, teacher burnout relates to lower student performance and lower teacher self-efficacy (Schwarzer \& Hallum, 2008; Shoji et al., 2016; Skaalvik \& Skaalvik, 2010). Teacher burnout indeed may have negative repercussions on student learning and achievement because exhausted teachers tend to detach themselves from their work and their students and to have reduced self-efficacy beliefs (Author \& Author, 2013a; Brouwers \& Tomic, 2000).

Burnout is a psychological reaction to exposure to a chronically demanding workplace characterized by physical, emotional and mental exhaustion and fatigue (Kristensen, Borritz, Villadsen, \& Christensen, 2005; Schaufeli \& Greenglass, 2001). When demands are perceived as exceeding resources, teachers feel exhausted and workload represents one of the most important precursors of burnout (Alarcon, 2011). Workload represents a challenge stressor, that is, it is potentially associated with both gains and losses for workers. Prolonged exposure to high workload, however, is strongly associated with physical and emotional depletion. In contrast, social support represents an important resource to cope with both work overload and burnout (Maslach, Schaufeli, \& Leiter, 2001).

Building on previous work by Author and colleagues (2015) and integrating it with findings of a recent meta-analysis (Luchman \& Gonzales-Morales, 2013), we propose a mediational model. More specifically, in the present paper we will outline the important role of organizational identification for the mobilization of social support. There is substantial 
evidence that workers with a strong organizational identification tend to receive more social support from colleagues (Author \& Author, 2012b). These employees can mobilize social relations to obtain help from their coworkers, and there is also evidence demonstrating that the activation of social support is an adaptive strategy to cope with work stressors (Halbesleben, 2006; Viswesvaran, Sanchez, \& Fisher, 1999). Thus, we hypothesize that teachers' sense of belonging to their school should increase the support received by colleagues, which in turn should reduce both workload and burnout. We will test this model in a large sample of Swiss teachers.

\section{Burnout in School Context}

Burnout represents "a state of physical, emotional and mental exhaustion that results from long-term involvement in work situations that are emotionally demanding" (Schaufeli \& Greenglass, 2001, p. 501). Research on this topic has revealed that while burnout can occur in each profession, it is more prevalent across the so called "helping professions", such as employees in health and social services, nurses, and teachers. In particular, teaching represent a very stressful profession (Kyriacou, 2001, Montgomery and Rupp, 2005). Putting together findings of 43 studies published in US, Schaufeli and Enzman (1998) reported the highest levels of emotional exhaustion for teachers compared to other important helping professions, such as employees in social services, nurses, or counselors (see for another comparative study: Kristensen, Borritz, Villadsen, \& Christensen, 2005). The consequences for teachers' health are massive. For example, Lodolo D'Oria and colleagues (2004) analyzing 3,447 medical examinations performed to certificate incapacity to work from 1992 to 2003 in a health district in Northern Italy found that teachers were between two to three times more likely to develop a psychiatric disorder than other professionals such as clerks, health care professionals, or blue collar workers. Shin, Noh, Jang, Park, and Lee (2013) conducted longitudinal analyses of depression and burnout in Korean teachers and found that teachers' 
initial levels of burnout led to subsequent depression symptoms 18 months later. Teachers suffering from burnout tend to be less effective and less satisfied with their job, and there is evidence that burnout is negatively related to self-efficacy, especially in the teaching occupation (Shoji et al., 2016).

Teachers generally start their careers in an enthusiastic way, dedicating their energy and commitment to student achievement, but, at a certain point, many teachers "lose interest, become cynical, and distance themselves from colleagues" (Tomic \& Tomic, 2008, p. 12). At this stage, teachers experience fatigue, nervousness, and emotional depletion, and develop self-doubts (Kyriacou, 2001). The problems are amplified by expectations by parents and the wider society which considerably increase professional and emotional demands (Schaufeli, Leiter, \& Maslach, 2009). As reported by many teachers interviewed in a recent qualitative study, student misbehavior or discipline problems represent "the most serious problem in school", because they make "teaching difficult to conduct" and also because the management of classroom discipline is "extremely energy intensive" (Skaalvik \& Skaalvik, 2015, p. 185). While the role of student misbehaviors and ineffective classroom management is generally recognized in teachers' burnout in theory, the link has been less clear in empirical studies to date (Betoret, 2009; Moreno-Abril et al., 2007). Teachers who have to manage students who show poor motivation and disruptive behaviors could continuously experience feelings of anger, frustration, and anxiety and these could in turn lead to or exacerbate emotional exhaustion (Aloe et al., 2014). Furthermore, as it was shown in a qualitative study on teachers who left their profession after only one year, along with difficulties with students and low salary, "teachers experienced a clear lack of support" (Gonzalez, Brown, \& Slate, 2008, p. 9). As a consequence, teachers might reduce job engagement and show lower patience for students' misbehaviors or finally decide to leave their profession (Gonzalez, Brown, \& Slate, 2008; Kyriacou, 2001). 


\section{The Social Identity Approach to Stress}

Organizational identification represents "the perception of oneness or belongingness to some human aggregate" (Ashforth \& Mael, 1989, p. 21). Following social identity theory, social groups such as organizations, schools, or work teams are not only features of the external world, but they are also internalized by the individual, contributing to a person's sense of self (Haslam, 2004). Hence, when a specific membership becomes salient in a certain context, employees should show favoritism for their organization, in terms of more engagement and collaboration (Ashforth, Harrison, \& Corley, 2008). Indeed, there is strong empirical evidence for the positive link between organizational identification on the one hand and extra-role behaviors, including helpful behavior toward colleagues, on the other (Riketta, 2005; Lee, Park, \& Koo, 2015). More recently, several authors used the social identity approach as a framework to understand the process of work stress and employees health (Author \& Author, 2012b). Lazarus and Folkman (1984) argued that stress occurs only when individuals perceive a stressor as potentially harmful and exceeding their coping abilities. Despite its great merit, a limitation of this conceptualization is to think of the stress process only in terms of individual dynamics. However, evidence suggests that people in the same work context "often come to share complaints relating to their work experience, and hence it is at the group (and not just the individual) level that such processes need to be understood and tackled" (Author \& Author, 2012b, p. 5). Organizational identification should relate to (lower) stress and strain in both direct and indirect ways. Directly, because a strong sense of belonging helps satisfy important human needs, such as the need for safety and belonging (Ashforth et al., 2008). Indirectly, because people who feel a strong sense of organizational membership will tend to perceive their colleagues more positively, which helps to be more collaborative and supportive to each other (Haslam, 2004). 
Consistently, a strong sense of organizational identity is positively related to job satisfaction and negatively related to stress and burnout (Author \& Author, 2014; Bizumic, Reynolds, \& Turner, 2009; Author \& Author, in press). There is also some evidence of the positive effect of school teachers' social identification on their well-being. For example, Author and Author (2002) found that teachers identification with their school, teams, or occupational groups were negatively related to teachers' physical symptoms, such as headaches and shoulder pains, and Bizumic and colleagues (2009) found a negative correlation between teachers' identification and depression. Recently, Author and colleagues (2015) found a negative indirect effect of school identification on burnout, via social support and collective efficacy.

\section{The Relation between Identification and Support}

Social support is a crucial resource in organizational contexts that can help cope with stressors (Halbesleben, 2006; Viswesvaran et al., 1999). Following the Conservation of Resources Theory (COR; Hobfoll, 1989) people seek to obtain, protect and increase their resources, which include everything evaluated as important for them. In particular, resources are important because they help employees to obtain new resources to cope with job demands. Following this theory, stress occurs only when resources are threatened with loss. A supportive climate at work can increase the probability to obtain help from coworkers in order to complete the tasks (Luchman \& González-Morales, 2013). High levels of task assistance among colleagues reduce the employees' perception of too few resources because workers "can mobilize the resources of others in their network to assist them when job demands are high" (Luchman \& González-Morales, 2013, p. 39). This means that social support represents a resource available for the employees among the other personal resources, but also it "can replace or reinforce other resources that have been lacking" (Halbesleben, 2006, p. 1134). 
However, the empirical relation between social support on the one hand and stress and strain on the other hand, appears to be rather weak. For example, in their meta-analysis, Viswesvaran and colleagues (1999) conclude that the direct effect of support on strain is "relatively modest" (p. 326). Similar results were also found by Halbesleben (2006) in the relation between support and burnout. Furthermore, social support may sometimes even have a negative and harmful effect on employees. For example, the interactions with colleagues or superior at work could unintentionally make employees more sensitive to the stressful situations and the negative emotions evoked, because employees could mainly focus "on what is wrong with the work environment during potentially supportive interactions" (Beehr et al., 2010, p. 46). Furthermore, employees could perceive the supportive behaviors toward themselves as a threat to their personal self-image, because under certain conditions, their colleagues' helping could make them feel inadequate and to be in an inferior position (Beehr et al., 2010). Finally, colleagues or supervisors could provide support to employees "who do not desire or want it, making the provision of support unwelcome" (Beehr et al., 2010, p. 46). In accordance with the social identity model of stress (Haslam, 2004), we argue that a shared social identity increases the likelihood to receive support from others, and, at the same time, provides the basis to evaluate and interpret helping behaviors by colleagues and supervisors in a positive spirit (Author \& Author, 2014a). A sense of belonging should increase the size of employees' social network, making more likely to obtain support. Indeed, to the extent that employees perceive themselves to share the same group identity, they should be more motivated to help each other (Author \& Author, 2012b). Furthermore, employees who are strongly identified should be more motivated to be supportive to ingroup members, in order to increase the overall success of their group. Finally, a strong common sense of membership should facilitate the understanding of appropriate and respectful ways to offer help (Haslam, 2004), and a common social identity should provide group members with 
a common interpretive framework inducing feelings of trust, and fostering the interpretation of support as being wholehearted and altruistic (Author \& Author, 2014a). For example, Häusser and colleagues during an experimental stressful situation in which people were exposed to the presence of others, found that participants with a salient group identity showed an attenuated cortisol reaction compared to participants with a salient personal identity (Author \& Author, 2012a). To confirm this, a meta-analysis has shown that organizational identification was positively related to helping towards colleagues (Riketta, 2005).

Furthermore, there is evidence of the mediating role of social support in the organizational identification-stress link (Jetten, Haslam, \& Haslam, 2012). We believe that these relations should also operate in the school context. Schools are indeed very structured organizations, with a hierarchy, with explicit duties and roles, with periodic meetings, collective aims and goals and in this sense we expect to find similar dynamics as have been found in other occupational settings. In particular, we expect that part of the teachers' identity should be related to their membership in their schools. Strongly identified teachers should therefore be more prone to cooperate with colleagues, including giving and receiving more social support. Furthermore, at least in Switzerland but also in many other countries, teachers are federal employees, their occupation is quite secure, career promotion is rare and salary depends only upon age. For these reasons, we expect that in the teaching profession, intrinsic factors (i.e., school identification, social support) should play a prominent role to influence teachers' attitudes and behaviors when facing stressors even more than in other organizations where other, more extrinsic factors (such as bonuses) also play a role. In line with this reasoning, there is already initial evidence for the relationships between identification, support and burnout among school teachers (Author \& Author, 2015). 
With the present research, we aim to replicate the mediating role of social support, but we will also extend existing knowledge by proposing reduced workload as a second key mediator of the identification-burnout link.

\section{The Relation between Support and Workload}

Social support can play a crucial role when job demands are high. In particular, workload and time pressure represent an "overload of demands at work" (Alarcon, 2011, p. 550). A prolonged exposition to high job demands is associated with negative consequences on the employees' health and well-being (Häusser, Mojzisch, Niesel, \& Schulz-Hardt, 2010). Indeed, employees who perceive that they have insufficient time or personal ability to fulfill a set of job tasks will tend to deplete their mental and physical energy, leading to emotional exhaustion, and indeed high workload represents one of the most important precursors of burnout (Alarcon, 2011).

Some researchers conceptualized workload as a challenge stressor together with similar constructs such as responsibility (LePine, Podsakoff, \& LePine, 2005). This type of stress is seen as potentially able to promote personal growth and achievement, and, indeed, is often empirically related to high employee motivation and performance, whereas hindrance stressors (e.g., role ambiguity, role conflict, etc.) are related to job dissatisfaction and turnover (LePine et al., 2005). However, this effort represents a personal cost for employees that over time could lead to excessive fatigue and exhaustion, activating a depletion process of the energies and the personal resources, and, leading, as a consequence, to ill-health (Alarcon, 2011; Podsakoff , LePine, \& LePine, 2007; Skaalvik, \& Skaalvik, 2011). For example, Moreno-Abril and colleagues (2007) found in a sample of Spanish teachers that after controlling for personality and socio-demographic variables, unlike other psychosocial variables (such as student misbehavior and superior support), workload remained a positive and significant predictor of teachers' psychiatric morbidity. Skaalvik and Skaalvik (2010), 
studying the relation between stressors, burnout and self-efficacy in a large sample of Norwegian teachers, found that time pressure had a larger impact on emotional exhaustion than other stressors, such as problems with student discipline or poor parent relationships. A recent meta-analysis on 116 studies conducted in the last fifteen years investigated the relation between demands, role conflict and ambiguity, student misbehavior and teacher burnout, found that work overload represented the strongest antecedent of emotional exhaustion (Stewart, 2015). Also, qualitative studies tend to outline overwork as one of the most prominent stressors for teachers (i.e., Diehl \& Carlotto, 2014, Skaalvik \& Skaalvik, 2015).

A supportive work environment should increase the availability of emotional and instrumental resources for employees who face high workload. First, support stimulates positive affect among colleagues, because people become aware that they are not alone to cope with their job demands and that they can express their feelings instead of suppressing them. In this sense, support can act as an adaptive emotion regulation strategy, because recipients could be facilitated to reappraise negative events (i.e. disruptive student behaviors), receiving encouragement for their efforts and being helped to focus on the positive emotions rather than negative ones. Furthermore, employees who perceive to be supported by colleagues can mobilize their colleagues' resources when needed. In fact, strong social support "facilitates task accomplishment through mobilizing social ties to obtain help and advice from other coworkers" when job load is particularly high or demanding (Luchman \& González-Morales, 2013, p. 39). In the school context, this means that a supportive environment should help teachers to more easily share experiences, problems, but also new didactic methods and disruptive student management strategies, which helps increasing individual resources to cope with stressors, and this in turn should decrease the individual feelings of exhaustion and depletion. Along this line, there is meta-analytic evidence that 
workload mediates the relation between colleague support and burnout (Luchman \& González-Morales, 2013).

We hypothesize that this mechanism will act for both work- and student-related burnout. While the first represents excessive fatigue and exhaustion related to the domain of work in general, the second is related to specific contact with students. Likely, the former could be influenced by many demands, such as workload, time pressure, etc., whereas the latter should be particularly related to student-specific workload, such as classroom management. Teacher-student interactions are very prominent and represent the "core business" of teaching. In this sense, working with children represents a large potential stressor for teachers, but at the same time it is also the major source of teachers' job satisfaction.

\section{Hypotheses}

In summary, we hypothesize that teachers who strongly identify with their school are more likely to experience support from their colleagues. Support will be negatively related to workload which, in turn, will positively relate to both work- and student-related burnout. Finally, organizational identification indirectly and negatively relates to both work- and student-related burnout through the serial mediating influence of colleague support and, in turn, workload. Figure 1 summarizes the hypothesized model:

H1: Organizational identification is positively related to colleague support.

H2: Colleague support is negatively related to workload.

H3: Workload is positively related to both dimensions of burnout, i.e. work- and student-related burnout.

H4: Organizational identification is negatively and indirectly related to both dimensions of burnout, mediated by (higher) colleague support and (lower) workload. 
We will also test alternative models of the interplay of the variables under study that are theoretically plausible.

\section{Method}

We tested our model in a large sample. Although to use "a convenience sample does not automatically disqualify a study from publication" (Wilkinson et al., 1999, p. 596), convenience samples could lead to selection biases, increasing the probability to select who are most likely to respond to the questionnaire without regard to their socio-demographic characteristics. In prevention to this possible bias, we send the survey to the total target population, i.e. all teachers in the Swiss Canton of Ticino.

\section{Participants}

We examined our hypotheses in a sample of school teachers in the Italian speaking region of Switzerland (Canton Ticino). The school system in Switzerland is run by the local government of each Canton. In fact, there is no centralized management of the education system at the Swiss national level. Furthermore, Ticino is the only canton where Italian is spoken by the majority of the population, while the two major languages spoken in the rest of Switzerland are German and French. This makes the population of school teachers of Ticino Canton interesting because having a common language makes teachers from Ticino in some ways comparable to teachers from Italy. However, at the same time, the cultural context of Ticino refers also to the central-northern French and German speaking regions. In the Ticino Canton attending school is compulsory until the age of $15\left(9^{\text {th }}\right.$ grade $)$. After that, pupils can choose between different types of vocational education and high school, the latter lasting four years. As for the type of contracts, there are two possibilities available to teachers: temporary and permanent contracts. Teachers may also serve as substitutes, for example during their training. Teachers are typically employed with permanent contracts but in Canton Ticino nearly a third $(32.5 \%)$ have a temporary contract. Generally, teamwork is encouraged in the 
school institutes. For example, even with differences between different school types, teachers within the same disciplinary group have to make periodical meetings in order to discuss school programs and activities. Especially pre-primary and primary school teachers collaborate on both didactical planning and specific projects. As in many other European countries, the teaching profession in Switzerland is characterized by relatively high job security, in which salaries depend on age and where only a horizontal career is possible (Author \& Author, 2003).

The survey has been sent to the total population of public school teachers of Canton Ticino $(N=5,317)$. Participants worked in pre-primary, primary, lower and upper secondary schools and schools for students with special needs. In Canton Ticino the educational system is comprehensive until lower secondary school and is differentiated in the upper secondary level. Teachers have been invited to participate through a letter sent by the Department of Education, School and Sport of Canton Ticino; the communication was also coordinated with unions and professional associations. The questionnaire was entirely confidential and ensured anonymity for respondents and was administered through an on-line platform in April 2014.

In the last two columns of Table 1 the percentages of sub-groups in our sample compared to the full population of the schoolteachers in Canton Ticino are presented. A total of 2,754 (51.8\% response rate) teachers participated. The 69 teachers of special education sector were excluded from further analyses, because they officially respond to the Department of special education needs, but are practically involved either in the primary or the middle school institutes. This double belonging could lead to confusion when accounting for variables such as "school sector". Thus, the final sample considered for the analyses comprised 2,685 schoolteachers (60.7\% female). Participants' average age was 44.38 years $(\mathrm{SD}=10.39)$, with an average school tenure of 18.05 years $(\mathrm{SD}=11.85)$. Seventy-one percent had a permanent contract and were working in kindergarten $(9.3 \%)$, elementary 
(26.4\%), middle (28.8\%), high (12.6\%), and vocational schools $(22.9 \%)$. Teachers from vocational schools and teachers with a percentage of working hours less than $50 \%$ were slightly under-represented (see Table 1) - otherwise, the sample was representative of the total population.

\section{Measures}

Organizational identification was measured with the six-item scale of Mael and Ashforth (1992) in the Italian version of Bergami and Bagozzi (2000). Responses were given on a five-point scale, ranging from "totally disagree" (1) to "totally agree" (5). Sample item: "I rather say 'we' than 'they' when talking about my school" $(\alpha=.81)$.

Colleague support was measured using four items from the scale of Edwards, Webster, van Laar, and Easton (2008; for the Italian validation, see Author \& Author, 2013b). Reponses were given on a five-point scale, ranging from "never" (1) to "always" (5). Sample item: "I get the help and support I need from colleagues" $(\alpha=.89)$.

To measure workload we used six out of eight items of the job demands dimension in the scale by Edwards and colleagues (2008; for the Italian validation see Author \& Author, 2013b). Reponses were given on a five-point scale, ranging from "never" (1) to "always" (5). Sample item: "I have to work very intensively", "I have unrealistic time pressures", "I have to neglect some tasks because I have too much to do" $(\alpha=.84)$. We refer to workload in this paper as the teachers' perception of their workload. This is an established antecedent of stress in the organizational literature (Häusser et al., 2010). However, we also controlled for actual workload in terms of working hours (see below).

To assess burnout we used two dimensions of the Italian validation of the Copenhagen Burnout Inventory (CBI: Kristensen et al., 2005; Author \& Author, 2013): work-related burnout, which refers to the degree of fatigue and exhaustion perceived by workers as being related to their work (7 items; e.g., "Does your work frustrate you?"; $\alpha=$ 
$.87)$; and student-related burnout, which refers to the degree of fatigue and exhaustion perceived by workers as being related to work with their students (6 items; e.g., "Are you tired of working with students?"; $\alpha=.84)$. Following the recommendations of Kristensen et al. (2005) for both dimensions and on the basis of the content of each question, we used two different five-option response formats, one for intensity (from $1=$ to a very high degree to 5 $=$ to a very low degree) and the other for frequency (from $1=$ always to $5=$ never/ almost never).

Control variables. We controlled for several variables that may affect the proposed relations but that were not of direct theoretical interest (Becker, 2005). First, we controlled for respondents' age and gender because in several studies both variables have been found to affect employees' burnout (e.g., Ng \& Feldman, 2010). Further, we controlled for type of contract (permanent vs contingent), because there is evidence that temporary employees tend to report higher psychological morbidity than permanent employees (Virtanen et al., 2005) and for the percentage of working hours which represent a measure of the actual workload, and for school type using dummy variables.

\section{Data analyses}

The measures' factorial structure was examined before testing our hypotheses. The proposed five-factor model with organizational identification, colleague support, workload, work- and student-related burnout, respectively, as separate but correlated factors showed an acceptable fit with the data $(\mathrm{CFI}=.96 ; \mathrm{RMSEA}=.065)$ and a significant better fit than all possible alternative models (best fitting alternative model: $\mathrm{CFI}=.94$; RMSEA $=.077$; full results are available from the first author).

We performed analyses by using both observed and latent variables. In particular, hierarchical multiple regression analyses were performed to test the hypotheses for observed variables by using the PROCESS macro by Hayes (2013; model 6). Additionally, Structural 
Equation Modelling, using LISREL 8.71 (Jöreskog KG, Sörbom, 2004) was used to repeat the analyses using latent variables. For the analysis on observed variables, we estimated two independent models, one for each burnout dimension, and we tested our hypothesized model against alternative models. To analyze indirect effects, we calculated $95 \%$ confidence intervals (CIs) based on bias-corrected bootstrap analyses with 1.000 repetitions. Finally, we ran two multi-group analyses in order to test if the hypothesized path analytic model was invariant across gender (male vs female) and type of contract (temporary vs permanent contract) sub-groups.

\section{Results}

Before testing our main hypotheses, we examined descriptive statistics. In particular, we conducted two t-tests for both gender and type of contract, and two MANOVAs in order to explore differences between school types and different working hours (for results details see Table 1). Table 2 reports the correlations among study variables. Organizational identification correlated positively and significantly with colleague support $(r=.25, p<.001)$ and negatively and significantly with both work- and student-related burnout $(r=-.07$, and $r$ $=-.11, p s<.001$, respectively), while it was not related to workload $(r=.01, p>.05)$. Colleague support was negatively and significantly related to workload, and work- and student-related burnout ( $r=-.19, r=-.27$, and $r=-.22$, $p s<.001$, respectively). Finally, workload was positively and significantly related to both work- and student-related burnout ( $r$ $=.54$, and $r=.32$, ps <.001, respectively).

Table 3 presents results of the mediation analysis with observed variables. We computed three models; two mediation models and one including the dependent variables. In each model, we first included control variables. All variables were mean centered before inclusion. As shown in the upper part of Table 3, we first computed the model for colleague support as the first mediator (M1). In support of Hypothesis 1, organizational identification 
was significantly related to colleague support $(b=.25, p<.001)$. Next, we computed the analyses for workload (M2), as our second mediator. Consistent with Hypothesis 2, colleague support was negatively related to workload $(b=-.16, p<.001)$. In this second model, also organizational identification was positively related to workload $(b=.05, p<.05)$. Finally, and in line with Hypothesis 3, in the third model which explained 35\% of the variance, workload was strongly and positively related to work-related burnout $(\mathrm{b}=.54, p<.001)$. In this final model, both organizational identification and colleague support were significantly and negatively related to work-related burnout $(\mathrm{b}=-.04, p<.05$; and $\mathrm{b}=-.16, p<.001$, respectively).

As can be seen in the lower part of the Table 3, we computed the indirect effects and related bootstrap analyses for the third model. The total indirect effect was negative, but, more importantly and in line with Hypothesis 4, the sequential indirect effect of organizational identification on work-related burnout via both mediators in series (colleague support and workload) was negative $(b=-.022,95 \%$ CI $[-.029,-.016])$. Organizational identification also had a small negative direct effect on work-related burnout $(b=-.04,95 \%$ CI [-.068, -.010]). Interestingly, there was also a significant, but positive indirect effect of organizational identification on work-related burnout through workload $(b=.03,95 \% \mathrm{CI}$ $[.008, .047])$

Results for student-related burnout are essentially the same $\left(R^{2}=.17, p<.001\right)$. In line with Hypothesis 3, workload (M2) was positively related to student-related burnout $(\mathrm{b}=.31$, $p<.001)$. Again, both organizational identification and colleague support were negatively related to student-related burnout $(b=-.08$ and $-.13, p<.001$, respectively). We computed indirect effects with respective CIs, and as shown in the lower part of Table 3 , the sequential indirect effect of organizational identification on student-related burnout via both mediators in series (support and workload) was significant $(\mathrm{b}=-.013,95 \%$ CI [-.017, -.009]) supporting 
Hypothesis 4. Finally, organizational identification had a negative and significant direct effect on student-related burnout $(b=-.08,95 \%$ CI $[-.110,-.043])$, and a positive and significant indirect effect on student-related burnout through workload $(b=.02,95 \% \mathrm{CI}$ $[.005, .029])$. We conducted all analyses also without controls, excluding these variables as a potential explanation of our findings to increase confidence in our empirical results (Becker, 2005). These analyses showed a very similar pattern of results, with a small increase in the size of the hypothesized sequential indirect effects for both work-related $(b=-.0248,95 \% \mathrm{CI}$ $[-.0319,-.0191])$ and student-related burnout $(\mathrm{b}=-.0146,95 \%$ CI $[-.0191,-.0109])$. Furthermore, as outlined in the introduction, our final model has been tested against several theoretically possible alternative models. None of the alternative models showed better fit or larger indirect effects as the proposed model. Results of alternative models are available from the first author.

Finally, we tested our model also using structural equation modeling (SEM) to confirm our results with latent variables which allows to control for measurement error. In order to test the sequential mediational hypothesis we fit our model via SEM (both measurement and structural model) in which the direct and indirect paths are estimated simultaneously (see Figure 2). Results showed that both paths were significant, from organizational identification to colleague support and workload, and from colleague support and workload to burnout. We computed the sequential indirect effect, and the Sobel z-test was significant for both work-related $(b=-.027, p<.001)$ and student-related $(b=-.018, p$ $<.001)$ burnout. We used an online calculator tool to compute the significance of these two sequential indirect effects ${ }^{1}$, which implements the formula by Taylor, MacKinnon, and Tein (2008). In both models, also the direct path from organizational identification and burnout was significant, which provides evidence for a partial mediation effect (Iacobucci, Saldanha,

\footnotetext{
${ }^{1}$ https://mattchoward.com/sobel-test-calculator-for-serial-mediation-sequential-mediation/
} 
\& Deng, 2007). To confirm this, we compared the fit of the model with both direct and indirect paths and the model with only the indirect path by using the Chi-square difference statistic. We found that the model without the direct path from organizational identification to burnout fit the data significantly worse for both work- $(\Delta \chi 2=13.31(1), p<.001)$ and studentrelated $\left(\Delta \chi^{2}=31.01(1), p<.001\right)$ burnout.

Additionally, we performed two multi-group analyses to compare our model across sub-groups. First, we compared the unconstrained and constrained model across gender subgroups (male vs female). We firstly computed the unconstrained model, in which structural relationships are specified in the same way across the subgroups, but the coefficients in the relationships are estimated independently for each group. Then we estimated the constrained model where the parameters (factorial structure and structural paths) across subgroups were constrained to be equal in both subgroups. We performed these analyses for both work- and student-related burnout. Finally, we compared the fit of the constrained model with the fit of the unconstrained model using the difference in Chi-square statistic. A significant difference was found for both work-related $(\Delta \chi 2=58.79(25), p<.05)$ and student-related $(\Delta \chi 2=49.40$ $(24), p<.05)$ burnout, showing that the factor loadings and path estimates for male and female teachers are different. In Table 4 we report the direct, indirect, and total effects of hypothesized paths analysis across gender sub-groups and in relation to both work- and student-related burnout. As we can see, the main differences are that direct relation of identification with colleague support is larger in male than female teachers $(.38 / .39$ vs $.29 / .29$, for work- and student-related burnout, respectively), while the direct relation of workload with burnout is larger for female than male teachers $(.61 / .41 \mathrm{vs} .52 / .34$, for workand student-related burnout, respectively). More importantly, all direct, indirect, and total effects of the organizational identification on both work- and student-related burnout were larger for male than female teachers. In particular, for male teachers the indirect effect of 
identification on burnout was significant and -.05 (work-related) and -.06 (student-related), respectively, in comparison to -.02 (and insignificant) for female teachers. Finally, similar differences between men and women emerged in relation to the direct, indirect, and total effects of colleague support on burnout, with higher scores for male than female teachers for both work-related and student-related burnout.

We conducted the same analyses by type of contract, but in this case no differences were found in the comparison between unconstrained and constrained models. In particular, no significant difference was found for work-related ( $\Delta \chi 2=33.95(25), p>.05)$ nor for student-related $(\Delta \chi 2=30.51(24), p>.05)$ burnout across teachers having a temporary versus permanent contract, which means that the unconstrained multi-group model is refused. Thus, we can conclude that the factor loadings and path estimates did not differ across these subgroups.

While there are many shared features in the teaching profession across school types, teachers in different schools have to cope with children with different needs and characteristics according to their stages of development. For this reason, we performed a further analysis by using observed variables. In particular, we run our model separately for each different type of school (kindergarten, elementary, middle, high, and vocational schools). In Table 5 we provide the results concerning the sequential indirect effect of organizational identification on burnout through the mediational link of both colleague support and workload. As can be seen, the sequential indirect effect was significant for each type of school and for both work and student-related burnout. However, the magnitude of this effect changes across school types. In particular, it is larger for teachers in kindergarten, elementary, and middle schools, and lower for teachers in high schools and vocational schools. Overall, the postulated indirect effect was marginal, although still significant $(.007, p$ $<.05)$, for student-related burnout in teachers working in high and vocational schools. 
Organizational identification was directly, significantly and negatively related to both work$(b=-.09, p<.05)$ and student-related $(b=-.11, p<.05)$ burnout in teachers in high schools, and to student-related $(b=-.08, p<.05)$ burnout for teachers working in middle schools, while in each of the other school types a significant direct relation between identification and burnout was not found.

\section{Discussion}

The aim of this study was to outline the positive role of organizational identification for the mobilization of social resources in the school context, and how this dynamic could positively affect teachers' stress (workload) and strain (burnout). Building on previous empirical work (Author \& Author, 2015; Luchman \& Gonzales-Morales, 2013) we tested a mediational model in which the teachers' sense of belonging to their school increased the likelihood of social support from colleagues. Support, in turn, was negatively related to workload which was finally related to lower levels of both work-related and student-related burnout. All findings emerged with and without controlling for a range of demographic characteristics rendering our results very stable and generalizable across types of schools, contract types, age, and gender of teachers. Our findings partially overlap with previous empirical work. In particular, we found that identification was related to burnout through support (as in Author \& Author, 2015) and that support was related to burnout through workload (as in Luchman \& Gonzales-Morales, 2013). However, our study goes beyond pure replication as we have combined previous research to a more comprehensive model including workload as a new mediator of the identification-burnout link. Thus, we believe that our findings make a contribution to research in work psychology in this respect. Furthermore, while the teachers' type of contract seems to be irrelevant in our model, we found that the social mechanism described seems to be more important for male than female teachers. In particular, we found that school identification could buffer against stress more strongly for 
male teachers. Finally, additional analyses revealed that the predicted relation was stronger for teachers working with younger students (from kindergarten to middle schools), than for teachers working in high schools and vocational schools. This is particularly true for the student-related burnout and for teachers in vocational schools.

This study makes a contribution to the literature by clarifying how the social identity framework could help to understand the stress process, even in a profession that, traditionally, is more individual in nature. Actually, especially in the elementary and middle school sectors, different pedagogic practices are being implemented that are more social in nature, such as team teaching or co-teaching. However, there is large heterogeneity among school sectors and among different school institutes within the same school sector. For example, traditional models of teaching prevail in high schools. Nevertheless, our results show the importance of the perception of being part of a social entity for the processes of interpretation and coping with stressors.

In particular, in the school working environment the important role played by collective group membership is probably related to the creation of a network of reciprocal positive relations among colleagues. Highly identified teachers will perceive themselves as more similar to their colleagues, and will be more prone to be collaborative and supportive to each other. Receiving support is one of the most important resources to cope with stressors because it increases the personal confidence to deal with future challenges and stressors (Halbesleben, 2006). As outlined by a teacher in a recent qualitative study "here, we are very close, and, if something isn't nice, I talk to the supervisor, we talk to the director... That's it, we're a team, and we help each other" (Diehl \& Carlotto, 2014, p. 749). This is particularly true when a strong and shared collective sense of belongingness exists. Indeed, social support could be seen also as a threat for the employee's self, while a shared social identity should facilitate acceptance of the others' help as testimony of the common belonging (Author \& 
Author, 2014a). A shared identity represents the basis for a common action against stressors (Author \& Author, 2012b), thus future studies could explore the possibility to expand the current model by introducing the variable of teachers' collective efficacy. In fact, there is evidence that teachers' self-efficacy decreases burnout (Betoret, 2009; Skaalvik \& Skaalvik, 2010), but there is also initial evidence that teachers' collective efficacy plays a role in this mechanism (Author \& Author, 2015).

In order to increase both school identification and thereby social support, schools could dedicate more importance to socialization strategies. In fact, younger teachers are often the most likely candidates to leave teaching because of the extreme workload and resulting burnout. One reason for this may be that young teachers tend to use more individualistic coping strategies than social ones, perhaps to show to live up to their own standards. This could be related to the professional identity as it is idealized at the beginning of the career, and is often characterized by unrealistic beliefs. There is evidence that such idealistic beliefs could be a precursor of teacher drop-out (Hong, 2010). As outlined by Skaalvik and Skaalvik (2015) the primary strategy used by younger teachers (27-34 years) to face stress was to "work hard to manage everything required of them and to be well prepared for their teaching" (p. 187), also avoiding to stay home when ill and sacrificing their social lives. One of the young teachers interviewed by the authors said: "When I am at work everything stands or falls on me. In a way, every day is an examination. If I am not well prepared, it reflects upon me. The two first years [as a teacher], I thought I could manage everything. I worked and worked and worked, at night, in the weekends and during the holidays" (p. 187). Thus a more social approach to the teaching duties could decrease the performance anxiety and the work overload among younger teachers. To newcomers, schools could propose a more social approach through different job socialization, for example facilitating the mentoring relations among older and younger teachers. Mentors could provide counseling on job-related 
problems, questioning the younger colleagues' unrealistic beliefs, and increase their wellbeing and self-esteem “by challenging protégés' negative self-views” (Eby, Allen, Evans, Ng, \& DuBois, 2008, p. 3). Furthermore, mentoring could increase the protégés' organizational identification too. There is meta-analytic evidence that mentoring relations have positive effect on protégés' health and performance (Eby et al., 2008). Furthermore, as outlined in a recent review on pre-service teachers' resilience, building strong social relations and support represent, among other aspects, an important contextual factor in order to increase the teachers capability to deal with educational challenges and to be able to experience enthusiasm and job satisfaction, and this is particularly true "for early career teacher resilience" (Mansfield, Beltman, Broadley, \& Weatherby-Fell, 2016, p. 81).

In our study, we conceptualized work stressors in terms of work overload and time pressure. In fact and in line with previous research conducted in the school context, workload has been shown to represent a major source of teachers' stress (Moreno-Abril et al., 2007; Skaalvik \& Skaalvik, 2010). However, in the school context many other stressors are conceivable. Of course, managing students' misbehavior or lack of motivation and discipline represents a challenging stressor for teachers, particularly during the first years of their career (Dicke et al., 2014; Kokkinos, 2007). However, the relationship with students at the same time represents a major source of intrinsic reward for teachers. In the above mentioned qualitative study, all interviewed teachers agreed that the "primary source of job satisfaction was working with children, the actual process of teaching, and seeing their pupils learn and develop" (Skaalvik \& Skaalvik, 2015, p. 188). Accordingly, in our first study we found that the average level of work-related burnout was higher than student-related burnout $(\mathrm{M}=2.38$ vs $\mathrm{M}=2.21 ; t(2684)=15.64 ; p<.001)$. Nevertheless, future studies should replicate our model and consider more specific stressors, as well as other potential constraints, such as work-family conflict. 
Our final model revealed a suppressor effect. Organizational identification was not related to workload directly, but when colleague support was added to the regression, the relation between identification and workload became positive and significant. Although the effect was relatively small, it means that a strong identification may lead to higher workload. Workload has been conceptualized as a challenge stressor, because it is associated with higher levels of motivation (LePine et al., 2005). This type of stress is related to the promotion of mastery and personal growth and has been found to relate to high levels of performance and job satisfaction (LePine et al., 2005). A strong sense of belonging could represent teachers' motivation to increase their efforts in order to cope with time pressure and overload. Indeed, strongly identified employees tend to perceive organizational goals and aims as their own and will increase their efforts to accomplish them ( $\mathrm{Ng} \&$ Feldman, 2008). This, however, could have a negative effect on employees' health and well-being over time (Author \& Author, 2012).

The present research also has some limitations which, in turn, may offer directions for future research. We compared our models with several alternative models that could also be theoretically justified. Even if our findings showed that the hypothesized model had the best fit with data, our study was cross-sectional in nature, so it would be desirable to retest our model in a longitudinal design to address the directionality of hypothesized links. This would be important as a recent study suggests that burned out teachers detach themselves from relationships and use avoidance as a coping strategy when faced with stressors and therefore "do not make efficient use of the support available to them" (Fiorilli, Albanese, Gabola, \& Pepe, 2017, p. 129), which may create a vicious circle. Furthermore, it is possible that colleagues' support is an antecedent of identification and not vice versa. In fact, teachers who perceive a strong sense of reciprocity (i.e. supportive colleagues), should therefore feel that their needs of esteem and affiliation are fulfilled and such feelings would "make employees 
more likely to embrace the organization as a part of their social identity" (Ng \& Sorensen, 2008, p. 252). Empirically, at least in our sample, we found that our model had the best fit compared to other theoretically founded models, and in this sense it seems that identification may be a precursor of support, because, as we argue a shared sense of belonging provides the basis to positively evaluate and interpret colleagues' helping behaviors. Finally, it is also possible that the relation between support and identification is reciprocal. Strongly identified employees should be more prone to act in a cooperative way (Haslam, 2004), but at the same time, to the extent that employees receive support from colleagues they should reinforce, over time, their sense of organizational belonging ( $\mathrm{Ng} \&$ Sorensen, 2008). Future longitudinal studies could bring light to this question.

Another limitation of our studies is related to the fact the all data originated by the same source (self-report questionnaires). Future investigations should use different sources, such as data regarding absence from work or physiological health indicators.

Using convenience samples is quite usual in empirical research, but this practice could lead to the selection bias. In prevention to this possible bias, we sent the survey to the full target population of teachers in Canton Ticino, collecting data from the 52\% of the teachers in that geographic area. For this reason, despite the limitations previously listed, together the facts that we used a very large sample, although not completely representative of the teachers population in this region of Switzerland, and that our findings remained stable across different control variables, make us confident that the results would also hold in studies using different designs.

It would be interesting to extend this model to all the 26 Cantons in Switzerland, by using the three main languages (German, French, Italian), in order to test possible cultural differences within the same country. Additionally, it could be interesting to compare the burnout levels measured in Ticino Canton with the teachers' burnout levels in Italy. While 
the language is the same, Swiss teachers and Italian teachers differ with respect to several other aspects (Fiorilli et al., 2017). For example, teachers in Switzerland receive among the highest salaries in Europe while Italian Teachers have among the lowest salaries (OECD, 2012). Also regarding the level of respect for teachers in different countries, it has been found that Swiss teachers receive twice as much respect in the Teacher Status Index compared with Italian teachers (see: Dolton \& Marcenaro-Gutierrez, 2013), and in Italy there is evidence of the impact of professional and social status on teachers burnout (Pedditzi \& Nonnis, 2014). In general, Italian teachers seem to be considerably more exposed to stressful environments than their Swiss colleagues, which means that social support may play an even more important role. For example, Fiorilli and colleagues found in a cross-cultural study that unsatisfactory support was more strongly related to emotional exhaustion in Italian compared to Swiss teachers (Fiorilli, Gabola, Pepe, Meylan, Curchod-Ruedi, Albanese, \& Doudin, 2015).

Furthermore, future studies could explore more concrete aspects about teamwork in schools, for example if teachers actually work in teams and how many meetings they usually attend. This aspect could be used as moderator of our hypothesized model. For example, we could expect that school identification would increase with more team participation, even if the team participation could be simultaneously a source of stress, overall when there is conflict among different teachers' educational view (Skaalvik \& Skaalvik, 2015).

The most important conclusion that we can draw from the results is that organizational identification can reduce teachers' stress by increasing the perception of social support and thereby reducing teachers' perceptions of workload. These findings could be used by school authorities and policy makers. Building formal and informal shared identities in schools may be a good strategy to reduce stress and burnout, because, as outlined by another respondent interviewed in the qualitative study previous mentioned, teachers could be helped by sharing new skills and competences: "forming groups of teachers during breaks, so 
that everybody can open up" (Diehl \& Carlotto, 2014, p. 749). However, this is in some way opposite to the most commonly used approach. In fact, typically, the individual teacher who suffers from ill-health and burnout is seen as the cause for his or her problems (e.g., having competence deficits, inappropriate coping). Therefore, the solution for burnout in schools is mostly seen in treating the individual teacher by asking him or her to attend stressmanagement courses or visit a health resort or to receive psychotherapy. While all these measures may be helpful and, in some cases, necessary, we truly believe that there are limitations to this approach and that they ignore the important dimension of social context. Thus, our approach would also include highlighting the social nature of teachers work life by strengthening shared social identities.

\section{References}

1 “Author \& Author (2001) [details removed for peer review]".

2 “Author \& Author (2002) [details removed for peer review]”.

3 "Author \& Author (2003) [details removed for peer review]".

4 "Author \& Author (2012) [details removed for peer review]".

5 "Author \& Author (2012a) [details removed for peer review]".

6 "Author \& Author (2012b) [details removed for peer review]".

7 “Author \& Author (2013) [details removed for peer review]”.

8 “Author \& Author (2013a) [details removed for peer review]".

9 “Author \& Author (2013b) [details removed for peer review]".

10 “Author \& Author (2014) [details removed for peer review]".

11 "Author \& Author (2014a) [details removed for peer review]". 
12 “Author \& Author (2015) [details removed for peer review]”.

13 “Author \& Author (in press) [details removed for peer review]".

14 Alarcon, G. M. (2011). A meta-analysis of burnout with job demands, resources, and attitudes. Journal of Vocational Behavior, 79, 549-562. doi: 10.1016/j.jvb.2011.03.007

15 Aloe, A. M., Shisler, S. M., Norris, B. D., Nickerson, A. B., Rinker, T. W. (2014). A multivariate meta-analysis of student misbehavior and teacher burnout. Educational Research Review, 12, 30-44. doi: 10.1016/j.edurev.2014.05.003

16 Ashforth, B.E., Harrison, S.H., \& Corley, K.G. (2008). Identification in organizations: An examination of four fundamental questions. Journal of Management, 34, 325-374. doi: $10.1177 / 0149206308316059$

17 Ashforth, B.E., \& Mael, F. (1989). Social identity theory and the organization. Academy of Management Review, 14, 20-39. doi: 10.5465/AMR.1989.4278999

18 Beehr, T. A., Bowling, N. A., \& Bennett, M. M. (2010). Occupational stress and failures of social support: When helping hurts. Journal of Occupational Health Psychology, 15, 45-59. doi: $10.1037 / \mathrm{a} 0018234$

19 Becker, T.E. (2005). Potential problems in the statistical control of variables in organizational research: A qualitative analysis with recommendations. Organizational Research Methods, 8, 274-289. doi: 10.1177/1094428105278021

20 Bergami, M., \& Bagozzi, R. P. (2000). Self-categorization, affective commitment and group self-esteem as distinct aspects of social identity in the organization. British Journal of Social Psychology, 39, 555-577. doi: 10.1348/014466600164633 
21 Betoret, F. D. (2009). Self-efficacy, school resources, job stressors and burnout among Spanish primary and secondary school teachers: A structural equation approach. Educational Psychology, 29, 45-68. doi: 10.1080/01443410802459234

22 Bizumic, B., Reynolds, K. J., \& Turner, J. C. (2009). The role of the group in individual functioning: School identification and the psychological well-being of staff and students. Applied Psychology: An International Review, 58, 171-192. doi:

10.1111/j.1464-0597.2008.00387.x

23 Brouwers, A. H. \& Tomic, W. (2000). A longitudinal study of teacher burnout and perceived self-efficacy in classroom management. Teaching and Teacher Education, 16, 239-253. doi: 10.1016/S0742-051X(99)00057-8

24 Carson, R. L., Baumgartner, J. J., Matthews, R. A., \& Tsouloupas, C. N. (2010). Emotional exhaustion, absenteeism, and turnover intentions in childcare teachers examining the impact of physical activity behaviors. Journal of Health Psychology, 15, 905-914. doi: 10.1177/1359105309360697

25 Dicke, T., Parker, P. D., Marsh, H. W., Kunter, M., Schmeck, A., \& Leutner, D. (2014). Self-efficacy in classroom management, classroom disturbances, and emotional exhaustion: A moderated mediation analysis of teacher candidates. Journal of Educational Psychology, 106, 569-583. doi: 10.1037/a0035504

26 Diehl, L., \& Carlotto, M. S. (2014). Knowledge of teachers about the burnout syndrome: Process, risk factors and consequences. Psicologia em Estudo, 19, 741-752. http://dx.doi.org/10.1590/1413-73722455415

27 Dolton, P., \& Marcenaro-Gutierrez, O. (2013). Varkey GEMS Foundation Global Teacher Staus Index. Retrieved online at: 
Https://www.varkeyfoundation.org/sites/default/files/documents/2013GlobalTeacherSt atusIndex.pdf

28 Eby, L. T., Allen, T. D., Evans, S. C., Ng, T., \& DuBois, D. (2008). Does mentoring matter? A multidisciplinary meta-analysis comparing mentored and non-mentored individuals. Journal of Vocational Behavior, 72, 254-26. doi:

10.1016/j.jvb.2007.04.005

29 Edwards, J. A., Webster, S., van Laar, D., \& Easton, S. (2008). Psychometric analysis of the UK health and safety executive's management standards work-related stress indicator tool. Work and Stress 22, 96-107. doi: 10.1080/02678370802166599

30 Fiorilli, C., Albanese, O., Gabola, P., \& Pepe, A. (2017). Teachers' emotional competence and social support: Assessing the mediating role of teacher burnout. Scandinavian Journal of Educational Research, 61, 127-138. doi: 10.1080/00313831.2015.1119722

31 Fiorilli, C., Gabola, P., Pepe, A., Meylan, N., Curchod-Ruedi, D., Albanese, O., \& Doudin, P. A. (2015). The effect of teachers' emotional intensity and social support on burnout syndrome. A comparison between Italy and Switzerland. Revue Européenne de Psychologie Appliquée/European Review of Applied Psychology, 65, 275-283. doi.org/10.1016/j.erap.2015.10.003

32 Gonzalez, L., Brown, M. S., \& Slate, J. R. (2008). Teachers who left the teaching profession: A qualitative understanding. The Qualitative Report, 13, 1-11.

33 Guglielmi, R. S., \& Tatrow, K. (1998). Occupational stress, burnout, and health in teachers: A methodological and theoretical analysis. Review of Educational Research, 68, 61-99. doi.org/10.3102/00346543068001061 
34 Hakanen, J. J., Bakker, A. B., Schaufeli, W. B. (2006). Burnout and work engagement among teachers. Journal of School Psychology, 43, 495-513. doi: 10.1016/j.jsp.2005.11.001

35 Halbesleben, J. R. B. (2006). Sources of social support and burnout: A meta-analytic test of the conservation of resources model. Journal of Applied Psychology, 91, 1134-1145. doi: 10.1037/0021-9010.91.5.1134

36 Haslam, S. A. (2004). Psychology in organizations: The social identity approach. London: Sage. doi: http://dx.doi.org/10.4135/9781446278819

37 Hayes, A. F. (2013). An introduction to mediation, moderation, and conditional process analysis: A regression-based approach. New York, NY: Guilford Press.

38 Häusser, J. A., Mojzisch, A., Niesel, M., \& Schulz-Hardt, S. (2010). Ten years on: A review of recent research on the Job Demand-Control (-Support) Model and psychological well-being. Work and Stress, 24, 1-35. doi: http://dx.doi.org/10.1080/02678371003683747

39 Hobfoll, S. E. (1989). Conservation of resources: A new attempt at conceptualizing stress. American Psychologist, 44, 513-524. doi: 10.1037/0003-066X.44.3.513

40 Hong, J. Y. (2010). Pre-service and beginning teachers' professional identity and its relation to dropping out of the profession. Teaching and Teacher Education, 26, 15301543. doi: 10.1016/j.tate.2010.06.003

41 Iacobucci, D, Saldanha, N., \& Deng, X. (2007). A Meditation on Mediation: Evidence that Structural Equations Models perform better than regressions. Journal of Consumer Psychology, 17, 140-154. doi: 10.1016/S1057-7408(07)70020-7

42 Jetten, J., Haslam, C., \& Haslam, S. A. (2012). The social cure: Identity, health, and wellbeing. Hove and New York, NY: Psychology Press. doi: 10.4324/9780203813195 
43 Jöreskog KG, Sörbom D. LISREL (Version 8.71), Scientific Software International. Chicago, IL; 2004.

44 Kokkinos, C. M. (2007). Job stressors, personality and burnout in primary school teachers. British Journal of Educational Psychological Society, 77, 229-43. doi: $10.1348 / 000709905 \times 90344$

45 Kristensen, T. S., Borritz, M., Villadsen, E. \& Christensen, K. B. (2005). The Copenhagen burnout inventory: A new tool for the assessment of burnout. Work \& Stress, 19, 192 207. doi: $10.1080 / 02678370500297720$

46 Kyriacou, C. (2001). Teacher stress: Directions for future research. Educational Review, 53, 27-35. http://dx.doi.org/10.1080/00131910120033628

47 Lazarus, R. S., \& Folkman, S. (1984). Stress, appraisal, and coping. New York, NY: Springer.

48 Lee, E. S., Park, T. Y., \& Koo, B. (2015). Identifying organizational identification as a basis for attitudes and behaviors: A meta-analytic review. Psychological Bulletin, 141, 1049-1080. 10.1037/bul0000012

49 LePine, J. A., Podsakoff, N. P., \& LePine, M. A. (2005). A meta-analytic test of the challenge stressor-hindrance stressor framework: An explanation for inconsistent relationships among stressors and performance. Academy of Management Journal, 48, 764-775. http://dx.doi.org/10.5465/AMJ.2005.18803921

50 Lodolo D'Oria, V., Giraldi, F. P., Della Torre, M., Fasano, A. I., Vizzi, F., Fontani, S., ... Frigoli, P. (2004). Is there any correlation between psychiatric disease and the teaching profession? [Quale rischio di patologia psichiatrica per la categoria professionale degli insegnanti?]. La Medicina del Lavoro, 95, 339-353. 
51 Luchman, J. N., \& González-Morales, M. G.(2013). Demands, control, and support: a meta-analytic review of work characteristics interrelationships. Journal of Occupational Health Psychology, 18, 37-52. doi: 10.1037/a0030541

52 Mael, F. A., \& Ashforth, B. E. (1992). Alumni and their alma mater: A partial test of the reformulated model of organizational identification. Journal of Organizational Behavior, 13, 103-123. doi: 10.1002/job.4030130202

53 Mansfield, C. F., Beltman, S., Broadley, T., Weatherby-Fell, N. (2016). Building resilience in teacher education: An evidenced informed framework. Teaching and Teacher Education, 54, 77-87. http://dx.doi.org/10.1016/j.tate.2015.11.016

54 Maslach, C., Schaufeli, W. B., \& Leiter, M. P. (2001). Job burnout. Annual Review of Psychology, 52, 397-422. https://doi.org/10.1146/annurev.psych.52.1.397

55 Montgomery, C., \& Rupp, A. A. (2005). A meta-analysis for exploring the diverse causes and effects of stress in teachers. Canadian Journal of Education, 28, 458-486. doi: $10.2307 / 4126479$

56 Moreno-Abril, O., de Dios Luna-del-Castillo, J., Fernandez-Molina, C., Jurado, D., Gurpegui, M., Lardelli-Claret, P., \& Galvez-Vargas, R. (2007). Factors associated with psychiatric morbidity in Spanish schoolteachers. Occupational Medicine, 57, 194-202. doi: 10.1093/occmed/kqm013

57 Ng, T. W. H., \& Feldman, D. C. (2008). Long work hours: A social identity perspective on meta-analysis data. Journal of Organizational Behavior, 29, 853-880. doi: 10.1002/job.536

$58 \mathrm{Ng}$, T. W. H., \& Feldman, D. C. (2010). The relationships of age with job attitudes: A meta-analysis. Personnel Psychology, 63, 677-718. doi: 10.1111/j.1744$6570.2010 .01184 . x$ 
$59 \mathrm{Ng}, \mathrm{T}$. W. H., \& Sorensen, K. L. (2008). Toward a further understanding of the relationships between perceptions of support and work attitudes. A Meta-Analysis. Group \& Organization Management, 33, 243-268. doi: 10.1177/1059601107313307

60 OECD (2012). Education at a glance. Retrieved online at:

\section{Https://www.oecd.org/edu/EAG\%202012_e-book_EN_200912.pdf}

61 Pedditzi, M. L., \& Nonnis, M. (2014). Fonti psico-sociali di stress e burnout a scuola: Una ricerca su un campione di docenti italiani [Psico-social sources of stress and burnout in school: A study on a Italian teachers'sample]. La Medicina del Lavoro, 105, 48-62.

62 Podsakoff, N. P., LePine, J. A., \& LePine, M. A. (2007). Differential challenge stressorhindrance stressor relationships with job attitudes, turnover intentions, turnover, and withdrawal behavior: A meta-analysis. Journal of Applied Psychology, 92, 438-454. doi: 10.1037/0021-9010.92.2.438

63 Riketta, M. (2005). Organizational identification: A meta-analysis. Journal of Vocational Behavior, 66, 358-384. doi: 10.1016/j.jvb.2004.05.005

64 Schaufeli, W. B., \& Enzmann, D. (1998). The burnout companion to study and research: A critical analysis. London: Taylor \& Francis.

65 Schaufeli, W. B. \& Greenglass, E. R. (2001). Introduction to special issue on burnout and health. Psychology and Health, 16, 501-510. doi: 10.1080/08870440108405523

66 Schaufeli, W. B., Leiter, M. P., \& Maslach, C. (2009). Burnout: 35 years of research and practice. Career Development International, 14, 204-220. doi:

\section{$10.1108 / 13620430910966406$}

67 Schwarzer, R., \& Hallum, S. (2008). Perceived teacher self-efficacy as a predictor of job stress and burnout: Mediation analyses. Applied Psychology: An International Review, 57, 152-171. doi: 10.1111/j.1464-0597.2008.00359.x 
68 Shin, H., Noh, H., Jang, Y., Park, Y. M., \& Lee, S. M. (2013). A longitudinal examination of the relationship between teacher burnout and depression. Journal of Employment Counseling, 50,124-137. doi: 10.1002/j.2161-1920.2013.00031.x

69 Shoji, K., Cieslak, R., Smoktunowicz, E., Rogala, A., Benight, C. C., \& Luszczynska, A. (2016). Associations between job burnout and self-efficacy: A meta-analysis. Anxiety Stress Coping, 29, 367-86. doi: 10.1080/10615806.2015.1058369

70 Skaalvik, E. M., \& Skaalvik, S. (2010). Teacher self-efficacy and teacher burnout: A study of relations. Teaching and Teacher Education, 26, 1059-1069. doi: 10.1016/j.tate.2009.11.001

71 Skaalvik, E. M., \& Skaalvik, S. (2011). Teacher job satisfaction and motivation to leave the teaching profession: Relations with school context, feeling of belonging, and emotional exhaustion. Teaching and Teacher Education, 27, 1029-1038. doi: 10.1016/j.tate.2011.04.001

72 Skaalvik, E. M., \& Skaalvik, S. (2015). Job satisfaction, stress and coping strategies in the teaching profession-what do teachers say? International Education Studies, 8, 181-192. http://dx.doi.org/10.5539/ies.v8n3p181

73 Stewart, T. M. (2015). The relationship between demands and resources and teacher burnout: A fifteen-year meta-analysis. Dissertation.

74 Taylor, A. B., MacKinnon, D. P., \& Tein, J.-Y. (2007). Tests of the three-path mediated effect. Organizational Research Methods, 11, 241-269. doi: $10.1177 / 1094428107300344$

75 Tomic, W. \& Tomic, E. (2008). Existential fulfillment and burnout among principals and teachers. Journal of Beliefs and Values, 29, 11-27. http://dx.doi.org/10.1080/13617670801928191 
76 Virtanen, M., Kivimäki, M., Joensuu, M., Virtanen, P., Elovainio, M., \& Vahtera, J. (2005). Temporary employment and health: A review. International Journal of Epidemiology, 34, 610-622. https://doi.org/10.1093/ije/dyi024

77 Viswesvaran, C., Sanchez, J. I., \& Fisher, J. (1999). The role of social support in the process of work stress: A meta-analysis. Journal of Vocational Behavior, 54, 314-334. doi: 10.1006/jvbe.1998.1661

78 Wilkinson, L., \& Task Force on Statistical Inference APA Board of Scientific Affairs. (1999). Statistical methods in psychology journals: Guidelines and explanations. American Psychologist, 54, 594-604. doi: 10.1037/0003-066X.54.8.594 
Table 1. Mean scores for study variables and differences across sub-groups in the teacher population in Southern Switzerland.

\begin{tabular}{|c|c|c|c|c|c|c|c|}
\hline & $\begin{array}{l}\text { Organizational } \\
\text { identification }\end{array}$ & $\begin{array}{l}\text { Colleague } \\
\text { support }\end{array}$ & Workload & $\begin{array}{l}\text { Work-related } \\
\text { burnout }\end{array}$ & $\begin{array}{l}\text { Student- } \\
\text { related } \\
\text { burnout }\end{array}$ & $\begin{array}{c}\text { N sub-sample } \\
\text { (population) }\end{array}$ & $\begin{array}{c}\text { \% sub-sample } \\
\text { (population) }\end{array}$ \\
\hline $\begin{array}{l}\text { T-Test Comparisons } \\
\text { Gender }\end{array}$ & $M(S D)$ & $M(S D)$ & $M(S D)$ & $M(S D)$ & $M(S D)$ & & \\
\hline Male & $3.59(0.81)$ & $3.65(0.77)$ & $2.80 * * *(0.66)$ & $2.37(0.72)$ & $2.23(0.75)$ & $1053(2020)$ & $39.3 \%(39.8 \%)$ \\
\hline Female & $3.65 *(0.78)$ & $3.79 * * *(0.81)$ & $2.71(0.68)$ & $2.39(0.72)$ & $2.20(0.71)$ & $1629(3059)$ & $60.7 \%(60.2 \%)$ \\
\hline \multicolumn{8}{|l|}{ Type of contract } \\
\hline Temporary & $3.60(0.77)$ & $3.85^{* * *}(0.81)$ & $2.64(0.70)$ & $2.24(0.68)$ & $2.05(0.70)$ & $766(1651)$ & $28.6 \%(32.5 \%)$ \\
\hline Permanent & $3.64(0.80)$ & $3.69(0.79)$ & $2.79 * * *(0.66)$ & $2.45^{* * *}(0.73)$ & $2.28 * * *(0.73)$ & $1916(3428)$ & $71.4 \%(67.5 \%)$ \\
\hline \multicolumn{8}{|l|}{ MANOVA Comparisons } \\
\hline \multicolumn{8}{|l|}{ Type of school } \\
\hline Kindergarten & $3.83^{\mathrm{a}}(0.75)$ & $3.99^{\mathrm{a}}(0.88)$ & $2.61^{\mathrm{c}}(0.64)$ & $2.39^{\mathrm{abc}}(0.72)$ & $2.14^{\mathrm{b}}(0.68)$ & $251(504)$ & $9.3 \%(9.9 \%)$ \\
\hline Elementary & $3.66^{\mathrm{b}}(0.75)$ & $3.77^{\mathrm{b}}(0.83)$ & $2.70^{\mathrm{bc}}(0.68)$ & $2.46^{\mathrm{a}}(0.73)$ & $2.31^{\mathrm{a}}(0.71)$ & $710(1228)$ & $26.4 \%(24.1 \%)$ \\
\hline Middle & $3.57^{\mathrm{bc}}(0.77)$ & $3.69^{\mathrm{b}}(0.75)$ & $2.77^{\mathrm{ab}}(0.65)$ & $2.44^{\mathrm{ab}}(0.71)$ & $2.32^{\mathrm{a}}(0.73)$ & 772 (1378) & $28.8 \%(27.2 \%)$ \\
\hline High & $3.51^{\mathrm{c}}(0.86)$ & $3.66^{\mathrm{b}}(0.81)$ & $2.87^{\mathrm{a}}(0.70)$ & $2.32^{\mathrm{bc}}(0.71)$ & $2.08^{\mathrm{b}}(0.75)$ & $338(575)$ & $12.6 \%(11.3 \%)$ \\
\hline Vocational & $3.65^{\text {bc }}(0.82)$ & $3.67^{\mathrm{b}}(0.75)$ & $2.75^{\mathrm{ab}}(0.70)$ & $2.27^{c}(0.72)$ & $2.08^{\mathrm{b}}(0.70)$ & $614(1394)$ & $22.9 \%(27.5 \%)$ \\
\hline \multicolumn{8}{|l|}{$\%$ Worked hours } \\
\hline Until $49 \%$ & $3.49^{\mathrm{a}}(0.85)$ & $3.76(0.75)$ & $2.59^{\mathrm{a}}(0.70)$ & $2.18^{\mathrm{a}}(0.66)$ & $2.07^{\mathrm{a}}(0.74)$ & 314 (919) & $11.7 \%(18.1 \%)$ \\
\hline From $50 \%$ to $79 \%$ & $3.60^{\mathrm{b}}(0.78)$ & $3.74(0.75)$ & $2.69^{\mathrm{b}}(0.63)$ & $2.34^{\mathrm{b}}(0.69)$ & $2.22^{\mathrm{b}}(0.72)$ & $796(1365)$ & $29.7 \%(26.9 \%)$ \\
\hline $80 \%$ or more & $3.67^{\mathrm{b}}(0.78)$ & $3.72(0.83)$ & $2.81^{\mathrm{c}}(0.69)$ & $2.45^{\mathrm{c}}(0.74)$ & $2.24^{\mathrm{b}}(0.72)$ & $1570(2713)$ & $58.6 \%(53.4 \%)$ \\
\hline Total & $3.63(0.79)$ & $3.73(0.80)$ & $2.75(0.68)$ & $2.38(0.72)$ & $2.21(0.73)$ & $2685(5079)$ & $52 \%$ \\
\hline
\end{tabular}

$* p<.05 ; * * * p<.001$. Different superscripts indicate mean differences (Tukey post-hoc; $p<.05$ ). 
Table 2. Correlations between study variables

\begin{tabular}{|c|c|c|c|c|c|c|c|c|c|c|c|c|c|c|c|}
\hline & 1 & 2 & 3 & 4 & 5 & 6 & 7 & 8 & 9 & 10 & 11 & 12 & 13 & 14 & 15 \\
\hline 1. Gender ${ }^{\mathrm{a}}$ & - & & & & & & & & & & & & & & \\
\hline 2. Age & $-.15^{* * *}$ & - & & & & & & & & & & & & & \\
\hline 3. Type of school $1^{\mathrm{b}}$ & $.25^{* * *}$ & $-.10^{* * * *}$ & - & & & & & & & & & & & & \\
\hline 4. Type of school $2^{c}$ & $.15^{* * *}$ & $-.06^{* *}$ & $-.19^{* * *}$ & - & & & & & & & & & & & \\
\hline 5. Type of school $3^{\mathrm{d}}$ & -.03 & $-.04^{*}$ & $-.20^{* * * *}$ & $-.38^{* * *}$ & - & & & & & & & & & & \\
\hline 6. Type of school $4^{\mathrm{e}}$ & $-.14^{* * *}$ & .03 & $-.12^{* * *}$ & $-.23^{* * *}$ & $-.24^{* * *}$ & - & & & & & & & & & \\
\hline 7. Type of school $5^{\mathrm{f}}$ & $-.19^{* * *}$ & $.15^{* * *}$ & $-.18^{* * *}$ & $-.33^{* * *}$ & $-.35^{* * *}$ & $-.21^{* * *}$ & - & & & & & & & & \\
\hline 8. Type of contract ${ }^{h}$ & .02 & $-.28^{* * *}$ & $-.05^{*}$ & -.01 & $-.14^{* * *}$ & $-.08^{* * * *}$ & $.25^{* * *}$ & - & & & & & & & \\
\hline 9. Worked hours $1^{\mathrm{i}}$ & $-.05^{* *}$ & .03 & $-.11^{* * *}$ & $-.14^{* * *}$ & .00 & -.01 & $.21^{* * *}$ & $.32^{* * *}$ & - & & & & & & \\
\hline 10. Worked hours $2^{\mathrm{j}}$ & $.23^{* * *}$ & $.06^{* * *}$ & .02 & .01 & -.00 & .02 & -.03 & $-.04^{*}$ & $-.24^{* * *}$ & - & & & & & \\
\hline 11. Worked hours $3^{\mathrm{k}}$ & $-.18^{* * *}$ & $-.08^{* * *}$ & $.05^{*}$ & $.08^{* * *}$ & .00 & -.02 & $-.10^{* * *}$ & $-.17^{* * *}$ & $-.43^{* * *}$ & $-.77^{* * * *}$ & - & & & & \\
\hline $\begin{array}{l}\text { 12. Organizational } \\
\text { Identification }\end{array}$ & .02 & $-.05^{*}$ & $.08^{* * *}$ & .02 & $-.04^{*}$ & $-.06^{* *}$ & .01 & -.02 & $-.07^{* * *}$ & -.02 & $.06^{* *}$ & - & & & \\
\hline $\begin{array}{l}\text { 13. Colleague } \\
\text { Support }\end{array}$ & $.09^{* * * *}$ & $-.10^{* * *}$ & $.11^{* * * *}$ & .03 & -.03 & -.04 & $-.04^{*}$ & $.09^{* * *}$ & .01 & .01 & -.01 & $.25^{* * *}$ & - & & \\
\hline 14. Workload & $-.07^{* * *}$ & .03 & $-.06^{* *}$ & -.04 & .02 & $.07^{* * * *}$ & .00 & $-.10^{* * *}$ & $-.08^{* * *}$ & $-.06^{* * *}$ & $.11^{* * *}$ & .01 & $-.19^{* * *}$ & - & \\
\hline $\begin{array}{l}\text { 15. Work-related } \\
\text { burnout }\end{array}$ & .02 & -.01 & .00 & $.06^{* *}$ & $.05^{*}$ & -.04 & $-.09^{* * *}$ & $-.13^{* * *}$ & $-.10^{* * *}$ & $-.04^{*}$ & $.10^{* * * *}$ & $-.07^{* * *}$ & $-.27^{* * *}$ & $.54^{* * *}$ & - \\
\hline $\begin{array}{l}\text { 16. Student-related } \\
\text { burnout }\end{array}$ & -.02 & $-.06^{*}$ & -.03 & $.08^{* * * *}$ & $.09^{* * *}$ & $-.07^{* * * *}$ & $-.10^{* * * *}$ & $-.14^{* * *}$ & $-.07^{* * *}$ & .00 & $.05^{*}$ & $-.11^{* * *}$ & $-.22^{* * *}$ & $.32^{* * * *}$ & $.69^{* * *}$ \\
\hline
\end{tabular}

Note. $N=2685$ (listwise). ${ }^{*} p<.05 .{ }^{* *} p<.01 .{ }^{* * *} p<.001$ (2-tailed).

${ }^{\mathrm{a}}$ gender coded: $0=$ male and $1=$ female $;{ }^{\mathrm{b}}$ Type of school $1=$ kindergarten; ${ }^{\mathrm{c}}$ Type of school $2=$ elementary; ${ }^{\mathrm{d}}$ Type of school $3=$ middle; ${ }^{\mathrm{e}}$ Type of school $4=$ high; ${ }^{\mathrm{f}}$ Type of school $4=$ vocational; ${ }^{\mathrm{h}}$ Type of contract: $0=$ permanent and $1=$ temporary; ${ }^{\mathrm{i}}$ Worked hours $1=<50 \% ;{ }^{\mathrm{j}}$ Worked hours $2=50-89 \% ;{ }^{\mathrm{k}}$ Worked hours $3=90 \%$ or more. 
Table 3. Indirect effect of $X$ on $Y$ through two mediators (M1 and M2) in series

\begin{tabular}{|c|c|c|c|c|}
\hline & $\begin{array}{c}\text { Colleague support } \\
\text { (M1) } \\
R^{2}=.09^{* * *} \\
\end{array}$ & $\begin{array}{c}\text { Workload } \\
(\mathrm{M} 2) \\
R^{2}=.06^{* * *} \\
\end{array}$ & $\begin{array}{c}\text { Work-related burnout } \\
\text { (Y) } \\
R^{2}=.35^{* * *}\end{array}$ & $\begin{array}{c}\text { Student-related burnout } \\
\text { (Y) } \\
R^{2}=.17^{* * *} \\
\end{array}$ \\
\hline & $b$ coefficient (SE) & $b$ coefficient $(S E)$ & $b$ coefficient $(S E)$ & $b$ coefficient $(S E)$ \\
\hline Gender $^{\mathrm{a}}$ & $.06 \quad(.03)$ & $-.02 \quad(.03)$ & $.05 \quad(.03)$ & $-.04 \quad(.03)$ \\
\hline Age & $-.00 \quad(.00)$ & $-.00 \quad(.00)$ & $-.00^{*}(.00)$ & $.00 \quad(.00)$ \\
\hline Type of school 1 (kindergarten) & $.28^{* * *}(.06)$ & $.15^{*}(.05)$ & $.19^{* *} \quad(.05)$ & $.16^{*} \quad(.05)$ \\
\hline Type of school 2 (elementary) & $.11^{*} \quad(.04)$ & $-.07^{*}(.04)$ & $.19^{* * *}(.03)$ & $.26^{* * *}(.04)$ \\
\hline Type of school 3 (middle) & $(.04)$ & $-.02(.04)$ & $.11^{*} \quad(.03)$ & $.20^{* * *}(.04)$ \\
\hline Type of school 4 (high) & $.07 \quad(.05)$ & $.07 \quad(.05)$ & $-.06 \quad(.04)$ & $-.08 \quad(.05)$ \\
\hline Type of contract ${ }^{b}$ & $.17^{* * *}(.04)$ & $-.09^{*}(.03)$ & $-.08^{*}(.03)$ & $-.12^{* *}(.03)$ \\
\hline Worked hours $2(50-80 \%)$ & $-.03 \quad(.05)$ & $.08 \quad(.05)$ & $.03 \quad(.04)$ & $.04 \quad(.05)$ \\
\hline Worked hours 3 ( $90 \%$ or more) & $-.04 \quad(.05)$ & $.19^{* * *}(.04)$ & $.06 \quad(.04)$ & $.00 \quad(.04)$ \\
\hline Organizational identification (X) & $.25^{* * *}(.02)$ & $.05^{*}(.02)$ & $-.04^{*}(.01)$ & $-.08^{* * *}(.02)$ \\
\hline Colleague support (M1) & & $-.16^{* * *}(.02)$ & $-.16^{* * *}(.02)$ & $-.13^{* * *}(.02)$ \\
\hline Workload (M2) & & & $.54^{* * *}(.02)$ & $.32^{* * *}(.02)$ \\
\hline \multicolumn{3}{|c|}{ Probing indirect effects } & $\begin{array}{c}\text { Work-related burnout } \\
\text { (WRB) }\end{array}$ & $\begin{array}{l}\text { Student-related burnout } \\
\text { (SRB) }\end{array}$ \\
\hline & Point estimate $(95 \%$ CI) & Point estimate (95\% CI) \\
\hline \multicolumn{3}{|c|}{ Organizational identification $\rightarrow$ Colleague support $\rightarrow$ WRB/SRB } & $-.039(-.0505,-.0306)$ & $-.032(-.0434,-.0229)$ \\
\hline \multicolumn{3}{|c|}{ Organizational identification $\rightarrow$ Workload $\rightarrow$ WRB/SRB } & $\mathbf{. 0 2 7}(.0084, .0471)$ & $.016(.0047, .0281)$ \\
\hline \multicolumn{3}{|c|}{ Organizational identification $\rightarrow$ Colleague support $\rightarrow$ Workload $\rightarrow$ WRB/SRB } & $-.022(-.0288,-.0159)$ & $-.013(-.0167,-.0092)$ \\
\hline \multicolumn{3}{|c|}{ Total indirect effects of organizational identification on WRB/SRB } & $-.033(-.0558,-.0124)$ & $\mathbf{- . 0 2 9}(-.0454,-.0138)$ \\
\hline
\end{tabular}


Table 4. Direct, indirect, and total effect comparisons across male and female subgroups

\begin{tabular}{|c|c|c|c|c|c|c|}
\hline & \multicolumn{3}{|c|}{ Male $N=1053$} & \multicolumn{3}{|c|}{ Female $N=1629$} \\
\hline & $\begin{array}{c}\text { Organizational } \\
\text { identification }\end{array}$ & $\begin{array}{c}\text { Colleague } \\
\text { support }\end{array}$ & Workload & $\begin{array}{c}\text { Organizational } \\
\text { identification }\end{array}$ & $\begin{array}{c}\text { Colleague } \\
\text { support }\end{array}$ & Workload \\
\hline & \multicolumn{3}{|c|}{$\begin{array}{c}\text { Work-related burnout/Student related } \\
\text { burnout }\end{array}$} & \multicolumn{3}{|c|}{$\begin{array}{c}\text { Work-related burnout/Student related } \\
\text { burnout }\end{array}$} \\
\hline $\begin{array}{l}\text { Colleague } \\
\text { support }\end{array}$ & & & & & & \\
\hline $\begin{array}{l}\text { Direct effect } \\
\text { Indirect effect }\end{array}$ & $.38 / .39$ & & & $.29 / .29$ & & \\
\hline $\begin{array}{l}\text { Total effect } \\
\text { Workload }\end{array}$ & $.38 / .39$ & & & $.29 / .29$ & & \\
\hline Direct effect & $.04 / .04$ & $-.14 /-.14$ & & $.04 / .04$ & $-.14 /-.14$ & \\
\hline Indirect effect & $-.05 /-.05$ & & & $-.04 /-.04$ & & \\
\hline Total effect & $-.01 /-.01$ & $-.14 /-.14$ & & $.00 / .00$ & $-.14 /-.14$ & \\
\hline Burnout & & & & & & \\
\hline Direct effect & $-.06 /-.14$ & $-.12 /-.13$ & $.52 / .34$ & $-.04 /-.08$ & $-.06 /-.07$ & $.61 / .41$ \\
\hline Indirect effect & $-.05 /-.06$ & $-.07 /-.05$ & & $-.02 /-.02$ & $-.08 /-.06$ & \\
\hline Total effect & $-.11 /-.20$ & $-.19 /-.18$ & $.52 / .34$ & $-.06 /-.10$ & $-.14 /-.13$ & $.61 / .41$ \\
\hline
\end{tabular}

Notes. Only the structural path estimates are showed. Results in italics are statistically not significant.

Table 5. Hypothesized indirect effects across different types of school.

\begin{tabular}{|c|c|c|}
\hline Probing indirect effects & $\begin{array}{l}\text { Work-related burnout } \\
\text { (WRB) }\end{array}$ & $\begin{array}{c}\text { Student-related burnout } \\
\text { (SRB) }\end{array}$ \\
\hline $\begin{array}{l}\text { Organizational identification } \rightarrow \\
\text { Colleague support } \rightarrow \text { Workload } \rightarrow \\
\text { WRB/SRB }\end{array}$ & Point estimate (95\% CI) & Point estimate (95\% CI) \\
\hline $\begin{array}{ll}\text { - Kindergarten school } & (N=251) \\
\text { - Elementary school } & (N=710) \\
\text { - Middle school } & (N=772) \\
\text { - High school } & (N=338) \\
\text { - Vocational school } & (N=614)\end{array}$ & $\begin{array}{l}\mathbf{- . 0 2 5}(-.0580-.0074) \\
\mathbf{- . 0 2 9}(-.0450-.0171) \\
\mathbf{- . 0 2 9}(-.0436-.0194) \\
\mathbf{- . 0 1 4}(-.0346-.0037) \\
\mathbf{- . 0 1 7}(-.0290-.0073)\end{array}$ & $\begin{array}{l}\mathbf{- . 0 1 8}(-.0410,-.0054) \\
\mathbf{- . 0 2 1}(-.0348,-.0109) \\
-.017(-.0272,-.0107) \\
-.007(-.0173,-.0015) \\
-.007(-.0138,-.0030)\end{array}$ \\
\hline Full sample & $-.025(-.0319-.0191)$ & $-.015(-.0191-.0109)$ \\
\hline
\end{tabular}

Notes. Results of analyses without controls. 
Figure 1. Theoretical Model Linking Organizational Identification to Work- and Studentrelated burnout.

\section{Hypothesized Model}

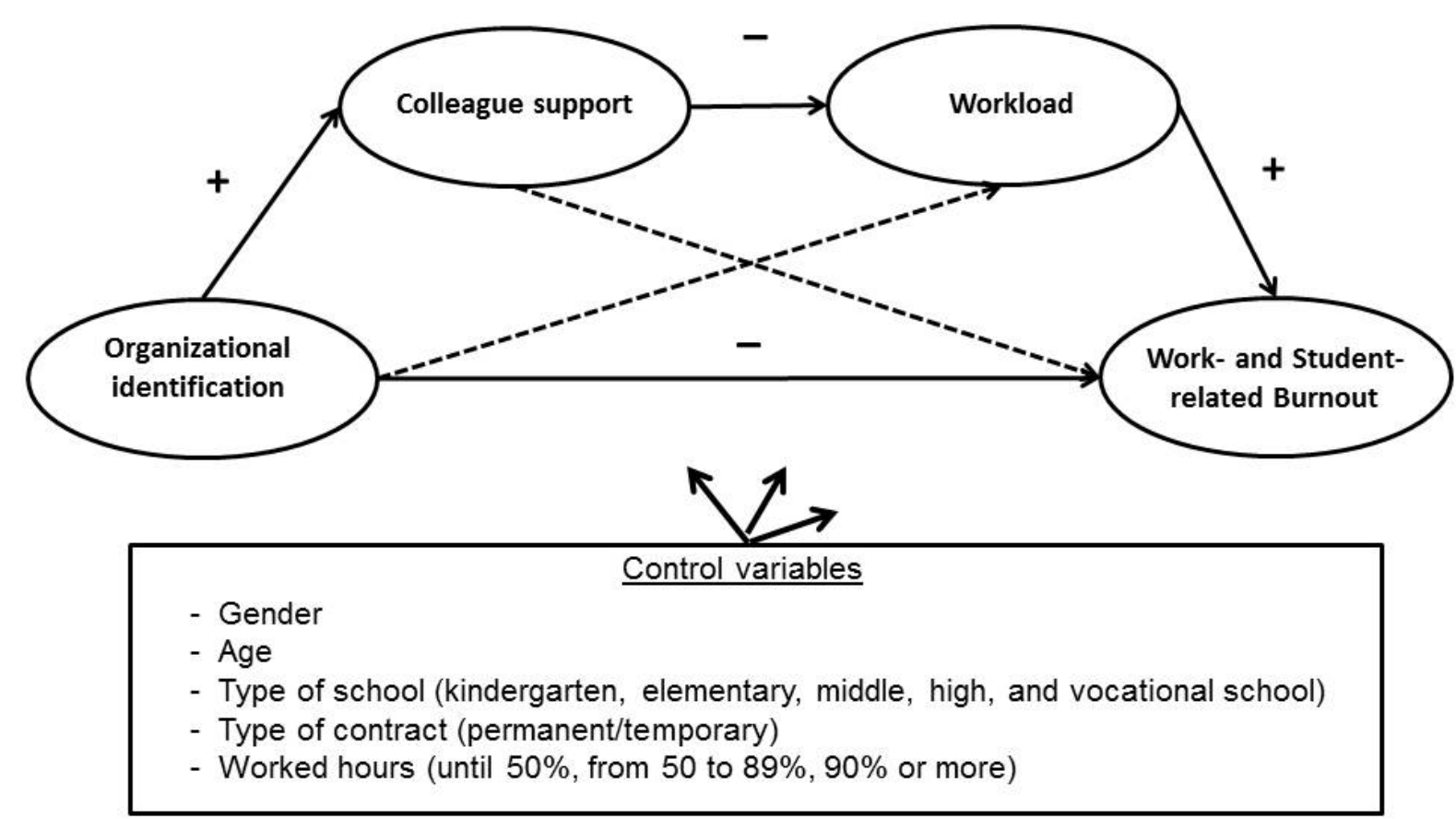

Note. Solid lines represent the links in the hypothesized model, whereas dashed lines represent additional paths involved in sequential mediation (Taylor, MacKinnon, \& Tein, 2007). 
Figure 2. Full Structural Equation Model for both work-related and student-related burnout.
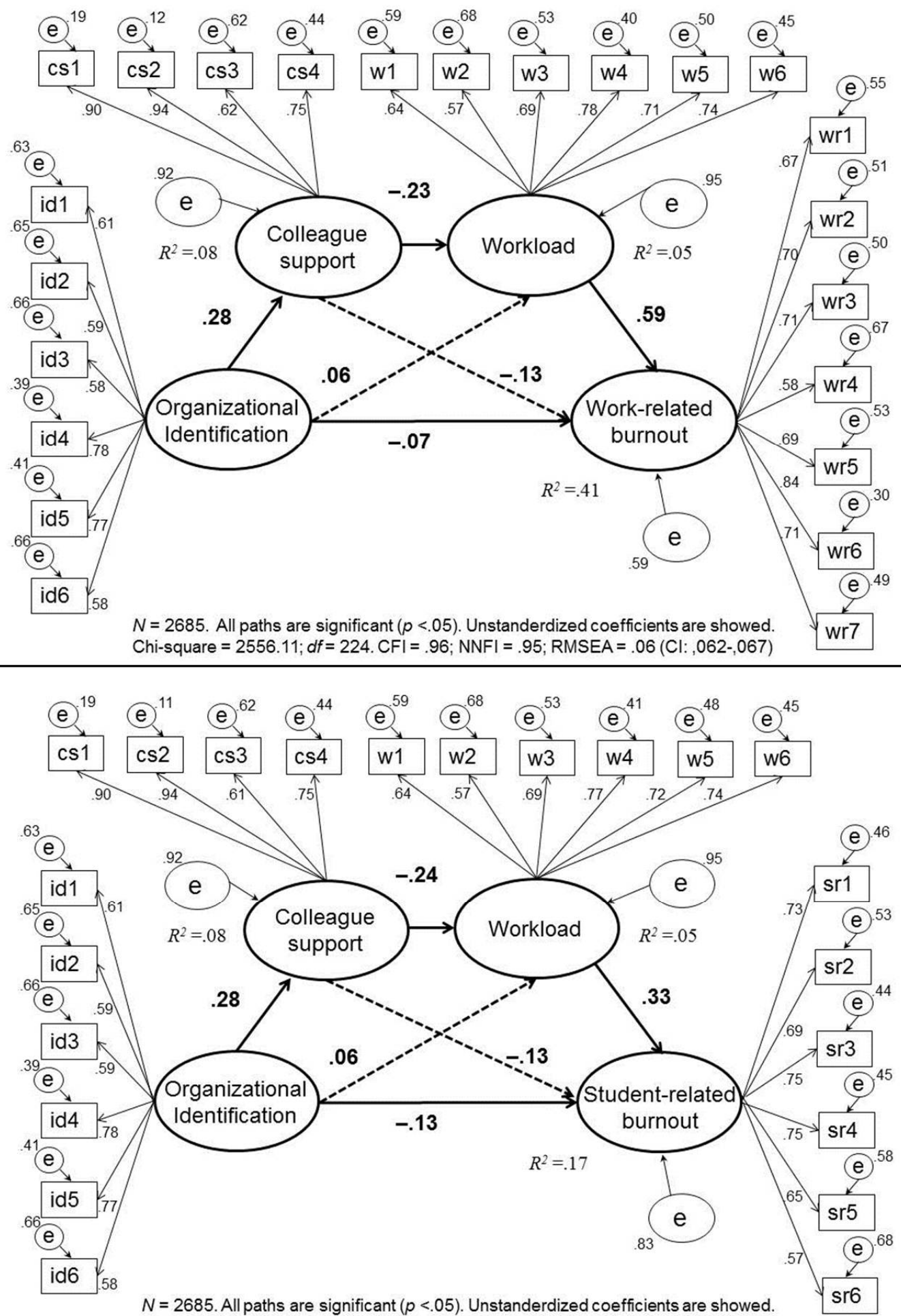

Chi-square $=2226.14 ; d f=203 . \mathrm{CFI}=.95 ; \mathrm{NNFI}=.94 ; \mathrm{RMSEA}=.06(\mathrm{Cl}:, 062-, 064)$

Note. Results without controls. Depicted are standardized values. 